\section{An unusual cause of elevated airway pressures}

To the Editor:

A two-week-old male infant in the NICU with bowel obstruction underwent urgent laparotomy. The patient was preoxygenated and premedicated with $0.02 \mathrm{mg}$ atropine $i v$. Vital signs were normal $\left(\mathrm{SpO}_{2} 100 \%, \mathrm{HR}\right.$ $145 \mathrm{bpm}, \mathrm{BP} 80 / 55 \mathrm{mmHg}$ ). Rapid sequence induction of anaesthesia and tracheal intubation were achieved with $10 \mathrm{mg}$ propofol, $4 \mathrm{mg}$ succinylcholine, and a $3.5 \mathrm{~mm}$ oral endotracheal tube (ETT) with a malleable stylet.

After intubation, the patient rapidly desaturated $\left(\mathrm{SpO}_{2} 20 \%\right)$ and became bradycardic (HR $\left.110 \mathrm{bpm}\right)$ without hypotension: Breath sounds were equal in both lungs and absent over the epigastrium. Diffuse inspiratory wheezes were heard. Peak airway pressure was $30 \mathrm{cmH}_{2} 0$. We decided to reintubate the trachea. As we prepared to remove the initial ETT, the nurse noticed that the stylet's plastic sheath was missing at its distal tip (sec Figure 1). Removal of the anaesthetic circuit $\mathrm{Y}$-connector revealed the missing piece lodged at the circuit end of the ETT. The $\mathrm{SpO}_{2}$ returned to $100 \%$, peak airway pressure decreased to $15 \mathrm{~cm} \mathrm{H}_{2} \mathrm{O}$, and $\mathrm{HR}$ increased to $150 \mathrm{bpm}$ with removal of the obstruction. The remainder of the anaesthetic course was uncomplicated.

The defect in the single-use stylet was located at a bend introduced into the stylet from multiple previous uses. This case, in which single-use equipment was reused, illustrates the potential danger when economic considerations override safety issues.

\section{Peter T-L. Choi MD}

Gary Rhydderch MD FRCPC

Department of Anaesthesia

McMaster University

Hamilton, Ontario.

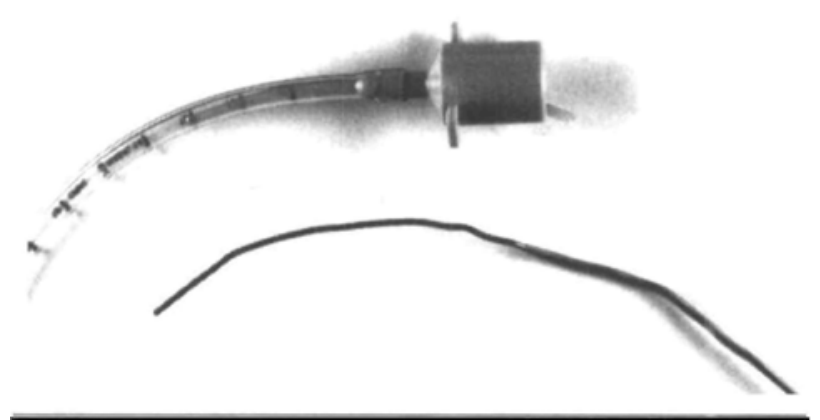

FIGURE 1 Endotracheal tube with obstruction from plastic sheath detached from flexible intubating stylet.

\section{Decision-making in anaesthesia: an imbroglio of science, anecdotes and art?}

To the Editor:

The recent editorial ${ }^{1}$ touches on a very relevant issue facing the profession - the battle between science and art. Clinical decisions should be based on science rather than being validated as an "art" based on anecdotal experiences or the exigencies of cost control. The "artists" claim that a cocktail of propofol and thiopentone is as good as the former alone, and cheaper without a clear demonstration of the bio-equivalence of such cocktails with the pure but more expensive new agents. ${ }^{2,3}$ The latest textbook in ambulatory anaesthesia ${ }^{4}$ even legitimises artistic practices with endearing terms such as "the propofol sandwich," without any supporting evidence. ${ }^{5}$ Recently, the same logic has been used to mix-and-match with alarming ingenuity $y_{Y}$ newer volatile agents with the older ones in spite of evidence to the contrary. ${ }^{6}$ Such practices arc "culinary" at best and "pharmacological promiscuity" at worst, and need to be discouraged.

The art of inhalation induction was rendered virtually obsolete in most adults and older children with the availability of intravenous induction agents and their ability to rapidly telescope the planes of anaesthesia. Desflurane permits a similar rapid telescoping of recovery within minutes, thereby rendering obsolete the art of emergence from anaesthesia as required with older agents. Faced with such scientific advances, why should we practice old fashioned art?

Until the profession demonstrates its commitment to evidence-based medicine there is a substantial risk that the specialty may be viewed as soft on science and audacious on art and anecdotes.?

Dr. Himat Vaghadia

Vancouver, BC, Canada

\section{REFERENCES}

1 Bevan DR. Neuromuscular relaxants (Editorial). Can J Anaesth 1997; 44: 1135-7.

2 Rashig S, Gallant B, Grace M, Jolly DT. Recovery characteristics following induction of anaesthesia with a combination of thiopentone and propofol. Can J Anaesth 1994; 41; 1166-71.

3 Lazar ER, Jolly DT, Tam YK, et al. Propofolthiopental stability study. Can J Anaesth 1997; 44: A21-B.

4 White PF. Ambulatory anaesthesia and surgery: past present and future. In: White PF (Ed.). Ambulatory Anaesthesia and Surgery, lst ed. London: WB Saunders Company Led, 1997: 3-34. 
5 Tang J, Wang B, Narușe R, et al. Does the propofol "sandwich" technique reduce PONV after inhalation anaesthesia. Anesth Analg 1997; 84: S554.

6 Gong $D H$, Weiskopf $R B$, Neumann MA, et al. In rats breathing from a nonrebreathing system, substitution of desflurane for isoflurane toward the end of anesthesia incompletely restores the time of recovery toward that of desflurane. Anesth Analg 1998; 86: 198-201.

7 Vellet AD, Lee D. Anecdote or science? Can Med Assoc J 1998; 158: 63-4.

\section{Fibreoptic laryngoscope blade}

To the Editor:

We would like to report the failure of a Heine \#4 fibreoptic laryngoscope blade (Heine Instruments (Canada), Ltd., Kitchener, Ontario) during a recent intubation.

A 42-yr-old, $92 \mathrm{~kg}$, ASA 2, lady presented for nasal and sinus surgery. No evidence of airway abnormality was detected pre-operatively. Anaesthesia was induced using protocol and a defasciculating dose of rocuronium before $120 \mathrm{mg}$ succinylcholine were given. An $8 \mathrm{~mm}$ Rae Mallinckrodt endotracheal tube was easily placed into the trachea using a Heine \#4 fibreoptic laryngoscope blade.

Upon withdrawing the laryngoscope from the mouth, the blade was closed against the handle. Immediately, a metallic sound was heard as a piece of the laryngoscope ricocheted off the anaesthetic machine and a quick search resulted in the discovery of a spring. The laryngoscope was examined thoroughly. The hookon base of the laryngoscope blade lacked the ball bearing portion of the hook-on locking apparatus (see Figure 2). The metal ball could not be found. Repeat visualisation of the patient's upper airway failed to locate the missing ball bearing. Similarly, radiographs of the patient's upper airway and chest were unsuccessful in locating the metal sphere. Eventually, the missing ball bearing was discovered in one of the partially open drawers of the anaesthetic machine.

The durability and structural integrity of laryngoscope blades are seldom a problem. Laryngoscope bulb and battery failure is common but laryngoscope blade structural failure is infrequent. ${ }^{3}$ It may exist in any facility where older Heine fibreoptic blades are in use.

Donald T. Jolly MD FRCP

Glenn Hawthorn RRT

Tony Wan BMET

Capital Health Authority

Department of Anaesthesia

University of Alberta Hospitals

Edmonton, Alberta, T6G 2B7

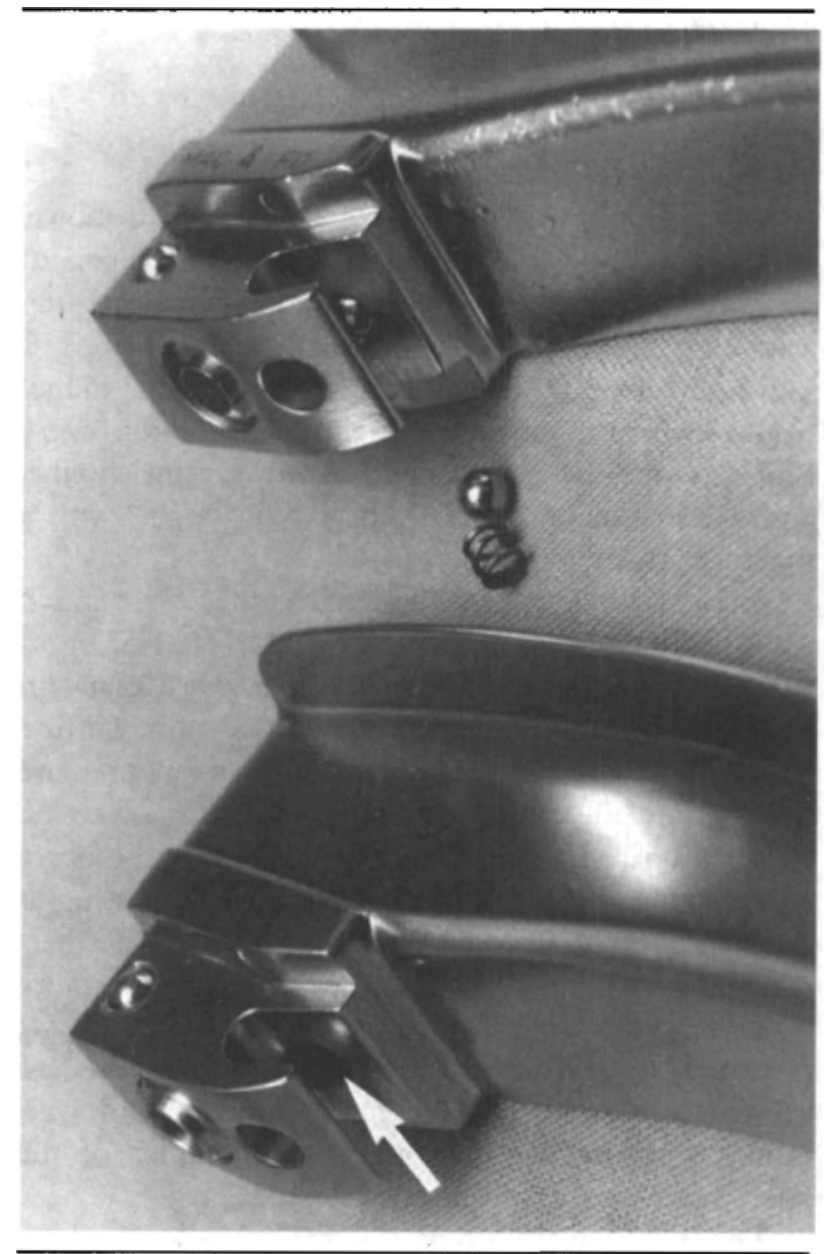

FIGURE 2 MAC \#4 Fibreoptic Heine laryngoscope blade

Top: Intact blade; Bottom: Blade missing the released ball bearing and spring (arrow)

(Photo courtesy. E. Poelzer)

\section{REPERENCE}

1 Gibson S, Kelly K. Pediatric laryngoscope blade failure (Letter). Anaesth Intensive Care 1996; 24: 724-5.

\section{Erratum}

Stein RD, Backman SB, Collier B, Polosa C. Bradycardia produced by pyridostigmine and physostigmine. Can J Anaesth 1997; 44: 1286-92.

On page 1287, first column, 9 th line from the bottom of the first paragraph, the word "unless" is incorrect and the sentence should read "In addition, whereas the neostigmine-induced bradycardia is blocked by selective nicotinic receptor antagonists, the block occurs at doses much greater than those at which these drugs act as selective antagonists. ${ }^{3 "}$ 